\title{
An Estimation of the Informal Economy in Morocco
}

\author{
Bourhaba Othmane ${ }^{1} \&$ Hamimida Mama ${ }^{1}$ \\ ${ }^{1}$ Faculty of Law, Economics and Social Sciences of Mohammedia, Hassan II University, Casablanca, Morocco \\ Correspondence: Bourhaba Othmane, Faculty of Law, Economics and Social Sciences of Mohammedia, Hassan \\ II University, BP 145, Mohammedia, Morocco. Tel: 212-643-376-972. E-mail: bourhabaothmane @ gmail.com
}

Received: June 13, 2016

doi:10.5539/ijef.v8n9p140
Accepted: July 11, 2016

Online Published: August 25, 2016

URL: http://dx.doi.org/10.5539/ijef.v8n9p140

\begin{abstract}
The paper attempts to both measure the size of the informal economy in Morocco and knows its tendency through the MIMIC approach. We calculated the size of the informal economy during the period 1999-2015. Our estimates show that this hidden part of economy constitutes $42.9 \%$ of the official GDP in 2015, and also show that there is a growth and a positive tendency of the informal economy in Morocco. The rise of corruption, the growth of the rate of urbanization and the tax burden play a determinant role in the magnification of the informal sector in Morocco.
\end{abstract}

Keywords: informal economy, MIMIC approach, Morocco, shadow economy

\section{Introduction}

Economic theory devotes more and more attention to the analysis of the informal economy. Indeed, questions about the informal economy have fed, until a very recent time, a vast literature of both theoretical and empirical around the world. Economic development models have constantly explained the role and the weight of the informal sector in the economies of the countries, gradually shifting their interest from the traditional sector theory (Lewis, 1954), to the models that evoke the informal sector as an important component in developing economies (Hart, 1973).

In Morocco, as in other developing countries, the informal sector represents a very important and a growing share of output and employment. Measuring the informal economy is a difficult task because individuals who work and produce in this sector try to hide their profit. The definition of the informal economy is not unified among specialists, but basically, every unregistered activity that generate a value added is considered informal, i.e. it includes all economic activities that escape taxes, do not include requirements or currency regulations, and avoid statistical reports.

If it has emerged in recent years a vast literature on the measure of the size of the informal sector, studies dealing with the informal sector in Morocco are not the case. There were, among others, three papers that treat the question of the size of shadow economy in Morocco. We will try to summarize the three works. First, very cited in the literature, the study of Schneider et al. (2010), examines the size of shadow economy in 162 countries around the world over the period 1999 to 2007. The study uses a MIMIC approach and estimates the size of the informal sector at $37 \%$ as a percentage of GDP. We have a second study which deals with the informal economy in Morocco, conducted by Alaoui Moustain (2004) using a MIMIC approach with data over the period between 1982 and 2000. Alaoui Moustain (2004) finds that the shadow economy in Morocco represents 38\% of GDP in 1998. Third, Elgin and Oztunali (2012) conducted a study using a dynamic general equilibrium model to calculate the size of informal economy in 161 countries around the world over the period 1950 and 2009. They found that the size of informal sector in Morocco represent 36\% of GDP in 1999. The common point between the 3 studies is that they provide, more or less, old estimates. There is no estimation of the informal sector in Morocco for the past decade. Our study provides a logical continuity of the literature by offering new and robust estimation.

The following text presents a measurement of the size of the informal economy in Morocco. Indeed, the measurement and the evaluation of the informal economy are an area of research that is always difficult and surrounded by debates and ambiguities. The non-measurability of the informal economy will lead us to national skewed statistics, such as the statistics on growth, unemployment, poverty, consumption and welfare. This implies a risk in the economic diagnosis of the country that induces erroneous economic decisions. 
Moreover, there are very few studies that evaluate the size of the informal sector in Morocco. Hence, our interest is to estimate the weight of this hiding part of the economy, following an indirect macro-modeling approach, called multiple indicators multiple causes (MIMIC).

The rest of the paper is organized as follows: In the second section of the paper we explain the outlines of the MIMIC approach and we build an empirical model which will be utilized to measure the size of the informal economy. Then we describe the data used in our study. Next, in the fourth section of the paper, we present the estimation and we discuss the econometric strategy. Finally, we provide conclusions.

\section{Methodology}

\subsection{MIMIC Modeling}

The method of the latent variable of Frey and Weck (1983), which relies on a set of explanatory variables, unlike other methods of indirect measurement which emphasis that the shadow economy can be modeled according to a few specific variables. The size of the shadow economy is estimated according to the evolution of variables which on the one hand, affect the magnitude and the growth of the shadow production, and on the other, for the variables that indicate the hidden activities in the economy. According to Schneider (2002) the MIMIC method is based on the statistical theory of unobserved variables, which considers that the causes and the indicators which are measured in a phenomenon are multiple. The unobserved variable, in this case, is the informal economy, and the model assumes that it is influenced by a number of different factors, as stated in Giles and Tedds (2002), this type of modeling has several advantages. The first is that it uses several data sources to collect as many components as possible of the informal economy; it's an important asset when we try to measure an "elusive" phenomenon like the informal economy. The second advantage is that the model can determine at once the size and the development of the informal economic activity over time. The third aspect of MIMIC is its potential to be deployed at the local level. So far, the model was used to measure the informal economy on the national level.

The MIMIC modeling studies are typically used as causes of the development of the informal sector: The tax burden, the level of regulation, public spending, and tax morality, and as indicators we often have: the money in circulation, GDP and the rate of participation of the active population.

\subsection{An Application of the MIMIC Model: Case of Morocco}

The informal sector is presented in our study as a latent variable that we seek to estimate through the MIMIC method. This method is a special case of the structural equation modeling (SEM). According to Hoyle (1995), SEM is defined as a global statistical approach which allows testing the assumptions that deal with the relationship between the observed variables and the latent variables.

We have created a structural equation model inspired by the studies (Note 1) that are concerned with the measurement of the size of the informal sector and the relationship between this sector and different macroeconomic variables. The variables constituting our model are the most significant variables in the estimations; in fact, we have proceeded to test the significance of several models to finally arrive at the best model.

The SEM can explain the relationship between, first: the latent variable $(\mu)$ and the determinants $\left(X_{t}\right)$.Then between the latent variable and the indicators $\left(Y_{t}\right)$.

The equation between the latent variable (informal economy) and its determinants (urbanization and tax burden $\left(X_{1}\right)$, the rate of urbanization $\left(X_{2}\right)$ and corruption $\left.\left(X_{3}\right)\right)$ is as follows:

$$
\mu=\beta_{0}+\beta_{1}\left(X_{1}\right)+\beta_{2}\left(X_{2}\right)+\beta_{3}\left(X_{3}\right)+e_{t}
$$

The equations that show the relationship between the informal economy $(\mu)$ and the indicators (GDP per Capita, $\left(Y_{1}\right)$ and between the informal and the money in circulation $\left.\left(\mathrm{Y}_{2}\right)\right)$, are written as follows:

$$
\begin{gathered}
Y_{1}=\theta_{1}+\alpha_{1} \mu+\varepsilon_{1} \\
Y_{2}=\theta_{2}+\alpha_{2} \mu+\varepsilon_{2}
\end{gathered}
$$

To simplify, the following figure shows the general structure of the MIMIC model: 


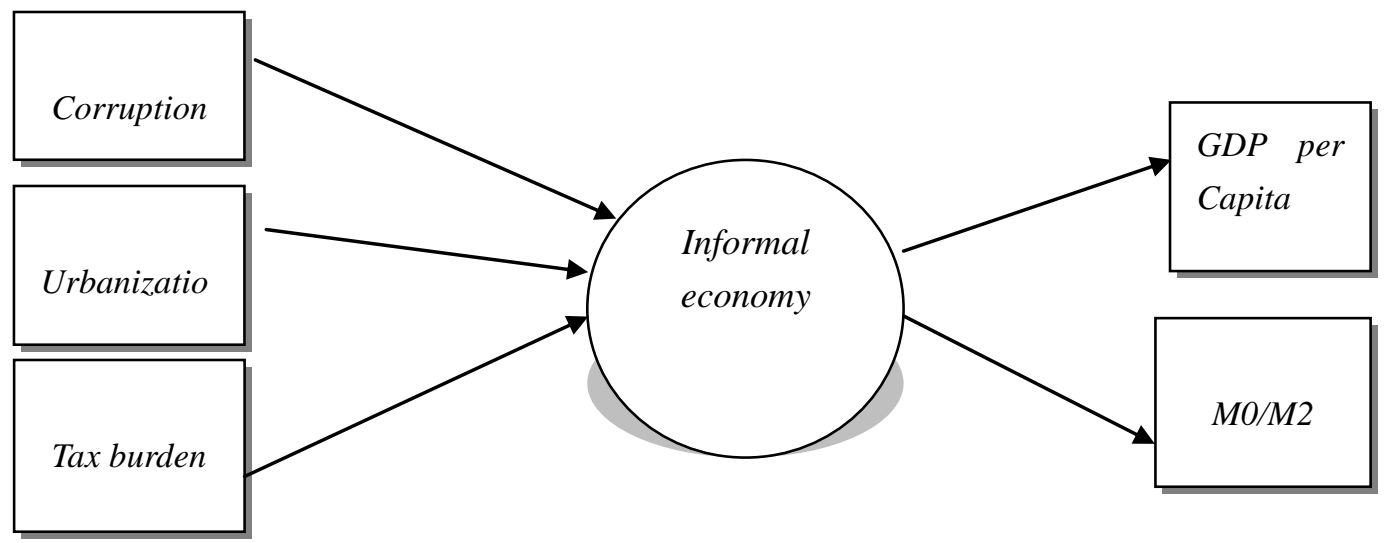

Figure 1. Structure of the MIMIC model used in our study

\section{Data Description}

To create our database, we used the database of the World Bank, the website of Transparency International (Note 2) (http://www.transparency.org), the website of Bank Al-Maghrib (www.bkam.ma) and also by our own calculations for some missing variables. Our analysis focuses on Morocco and the data used are for time intervals between 1999 and 2015.

The MIMIC method requires two types of variables. Some explain the causes and others are indicator variables of the latent variable. The majority of indicators and causes, used in the case of this study are derived from the literature which deals with the subject.

\subsection{The Causes of the Informal Sector}

The tax burden $\left(X_{1}\right)$. The assumption is that each time that the tax burden increases, the informal sector grows. This variable is, therefore, among the major causes that motivate individuals to go into the informal sector, this is true, at least for economists who seek to measure the size of the informal economy, since it is the most variable used in the literature which deals with this subject. The tax burden is measured by tax revenue as a percentage of GDP.

The urbanization rate $\left(X_{2}\right)$ represents the share of people living in an urban area in the country's total population. We assume that there is a causal relationship between urbanization and the size of the informal economy. According to Elgin and Oyvat (2013), the relationship between the informal sector and urbanization takes the form of a Kuznets curve, that is to say, the size of the informal sector increases in the early stages of urbanization then at some point, it will tend to fall in an advanced stage of urbanization.

Corruption Perceptions Index $\left(X_{3}\right)$. This index measures the degree of corruption in the public sector in each country. It is calculated annually by Transparency International. Our hypothesis here tries to argue that corruption has a positive effect on the size of the informal sector, in other words, every time the level of corruption increases, the size of the informal sector increases. The Corruption Perceptions Index gives the perceived level of corruption on a scale from 0 (highly corrupt) to 100 (very clean). So, the increase in the value of this index means the decrease of corruption. This index measures the "cleanliness" of public sector corruption. Therefore, the expected sign of the coefficient associated with $\left(X_{3}\right)$ in the regression would be a negative sign.

\subsection{Informal Sector Indicators}

We used two variables as indicators of the latent variable (informal economy). First, per capita GDP (in constant local currency units). Second, the ratio M0 (currency in circulation) M2 (Sight deposits).

The choice of GDP per capita $\left(Y_{1}\right)$ as an indicator of informal activity is motivated by the fact that there is a relationship between GDP per capita and the informal economy. Although the direction of the relationship is not clear in the literature (Note 3). An increase in the per capita GDP official can induce an increase in demand for goods and services in the informal economy. It is assumed that the sector size is influenced by the level of development. GDP per capita is considered as a proxy of economic development level.

Following Dell'Anno (2007), we used GDP per capita as a reference variable; otherwise, the associated coefficient will be set at a non-zero value, since the latent variable is not measurable. Hence, we are in the need 
to select its unit of measure (Note 4). The data on GDP per capita were collected from the World Bank database.

The second indicator of the informal sector is the ratio M0/M2 $\left(\mathrm{Y}_{2}\right) . \mathrm{M} 0 / \mathrm{M} 2$ is calculated as the ratio of currency in circulation and sight deposits. We used this ratio to get an index that provides information on the share of cash in the economy. It serves as an indicator of informality because transactions in the informal sector are generally made in cash. The increase of currency in circulation, which cannot be explained by "natural" factors, is attributed to the increase of the informal economy. We assume, then, that increasing M0/M2 would be an indication of the increase in the informal economy.

All variables used in this estimation are continuous. We summarize data in the following table:

Table 1. List of variables

\begin{tabular}{cc}
\hline Labels of the used variables & Signification \\
\hline $\mathrm{Y}_{1}$ & GDP per Capita \\
$\mathrm{Y}_{2}$ & The money supply M0 divided by M2 \\
$X_{1}$ & Income taxes by GDP \\
$X_{2}$ & Urbanisation rate \\
$X_{3}$ & Corruption Perceptions Index \\
\hline
\end{tabular}

\section{Results}

\subsection{Estimation Results}

Table 2 shows the results of the MIMIC model. This last is estimated by log through the maximum likelihood method. All variables are significant at $\mathrm{p}$-value $<0.05$, the variables have the expected signs and adjustment indicators show that the quality of the model is acceptable. Amos software is used for the calculations.

Table 2. Estimation of the model coefficients

\begin{tabular}{lccc}
\hline Model & $\begin{array}{c}\text { Corruption } \\
(\mathrm{p} \text {-value })\end{array}$ & $\begin{array}{c}\text { Urbanization } \\
(\mathrm{p} \text {-value })\end{array}$ & $\begin{array}{c}\text { Tax burden } \\
\text { (p-value })\end{array}$ \\
\hline MIMIC & $-0,209$ & 3,711 & 0,114 \\
& $(0.000)$ & $(0.000)$ & $(0.010)$ \\
\hline
\end{tabular}

Source: the authors' calculations.

Table 3. Model fit

\begin{tabular}{cccccc}
\hline Model & Chi-square & Degree of freedom & GFI & CFI & RMR \\
\hline MIMIC & 22,71 & 2 & 0,76 & 0.883 & 0,001 \\
\hline
\end{tabular}

Source: the authors' calculations.

\subsection{Benchmarking}

The Benchmarking is an essential step in every estimate of the informal sector through the MIMIC method. It aims to convert the coefficients estimated by the SEM to absolute values that quantify the size of the informal economy as a percentage of GDP. There are several benchmark procedures (Note 5) used in the literature that focus on the estimated size of the informal sector by the MIMIC method. We have chosen Dell'Anno's (2007) benchmark, which is widely used in the empirical studies that deal with the size of the informal economy.

The base year is 2000 because in this year there exists an estimate of the informal sector in Morocco of Schneider, Buehn, and Montenegro (2010), and it's the article the most cited in the literature that focuses on the measurement of the informal sector through the MIMIC method. This article assesses the informal economy in $36.40 \%$ of GDP in 2000. Some similar results were obtained by Alaoui Moustain (2004) and Elgin and Oztunali (2012), who estimated the informal sector in Morocco in 2000 by, respectively, 37.28\% and 35.64\% of GDP.

We substitute $Y_{1}$ and $\mu$ in equation (2) by the index of the changes of the GDP in 2000 and the index of changes in the informal sector GDP in 2000.we obtain the following measurement equation: 


$$
\frac{G D P_{t}-G D P_{t-1}}{G D P_{2000}}=\theta_{1}-\frac{\widetilde{\mu}_{t}-\widetilde{\mu}_{t-1}}{G D P_{2000}}
$$

The coefficients of the structural model are used to obtain the index of changes in GDP, with the following equation:

SEM:

$$
\frac{\widetilde{\mu}_{t}}{G D P_{2000}}=0.11 X_{1 t}+3.71 X_{2 t}-0.20 X_{3 t}
$$

Dell'Anno (2007) uses the following formula to estimate the size of the informal economy as a percentage of GDP:

$$
\frac{\widetilde{\mu}_{t}}{G D P_{2000}} \llbracket \frac{\mu_{2000}^{*}}{G D P_{2000}} \frac{G D P_{2000}}{\widetilde{\mu}_{2000}} \rrbracket \frac{G D P_{2000}}{G D P_{t}}=\frac{\widehat{\mu}_{t}}{G D P_{t}}
$$

Where:

$\frac{\widetilde{\mu}_{t}}{\operatorname{GDP}_{2000}}:$ Index calculated with Equation (5).

$\frac{\mu_{2000}^{*}}{\operatorname{GDP}_{2000}}$ : The benchmark estimation (exogenous) for the informal economy. It's equal to $36.4 \%$.

$\frac{\widetilde{\mu}_{2000}}{\mathrm{GDP}_{2000}}:$ Index calculated from equation (5) for the base year (2000).

$\frac{\mathrm{GDP}_{2000}}{\mathrm{GDP}_{\mathrm{t}}}$ : This index converts the index of the informal economy as changes respect to the base year in the informal economy respect to current GDP.

$\frac{\widehat{\mu}_{\mathrm{t}}}{\mathrm{GDP}_{t}}$ : Estimating the size of the informal sector as percentage of GDP.

It should be noted that there is not, so far, a theoretical framework of a benchmark for the MIMIC approach. Each benchmark procedure for converting the index estimates the informal economy by MIMIC model in absolute values, led to a different result as Breusch (2005b) highlights.

\subsection{Research Findings}

Table 4 presents the estimates of the informal economy in Morocco between the period 1999 and 2015.

Table 4. estimation of the informal sector

\begin{tabular}{lccccccccc}
\hline Years & $1999-2000$ & $2001-2002$ & $2003-2004$ & $2005-2006$ & $2007-2008$ & $2009-2010$ & $2011-2012$ & $2013-2013$ & 2015 \\
\hline Informal economy & $37.41 \%$ & $38.09 \%$ & $38.83 \%$ & $39.53 \%$ & $40.16 \%$ & $40.98 \%$ & $41.64 \%$ & $42.28 \%$ & $42.91 \%$ \\
\hline
\end{tabular}

Source: the authors' calculation.

According to our results the informal sector has grown in Morocco from 37\% in 1999 to $43 \%$ in 2015. The size of the informal sector has a low positive trend with a slope equal to 0.003 .

Figure 2 presents a comparison between our results and results of Schneider et al. (2010) and Alaoui Moustain (2004). 


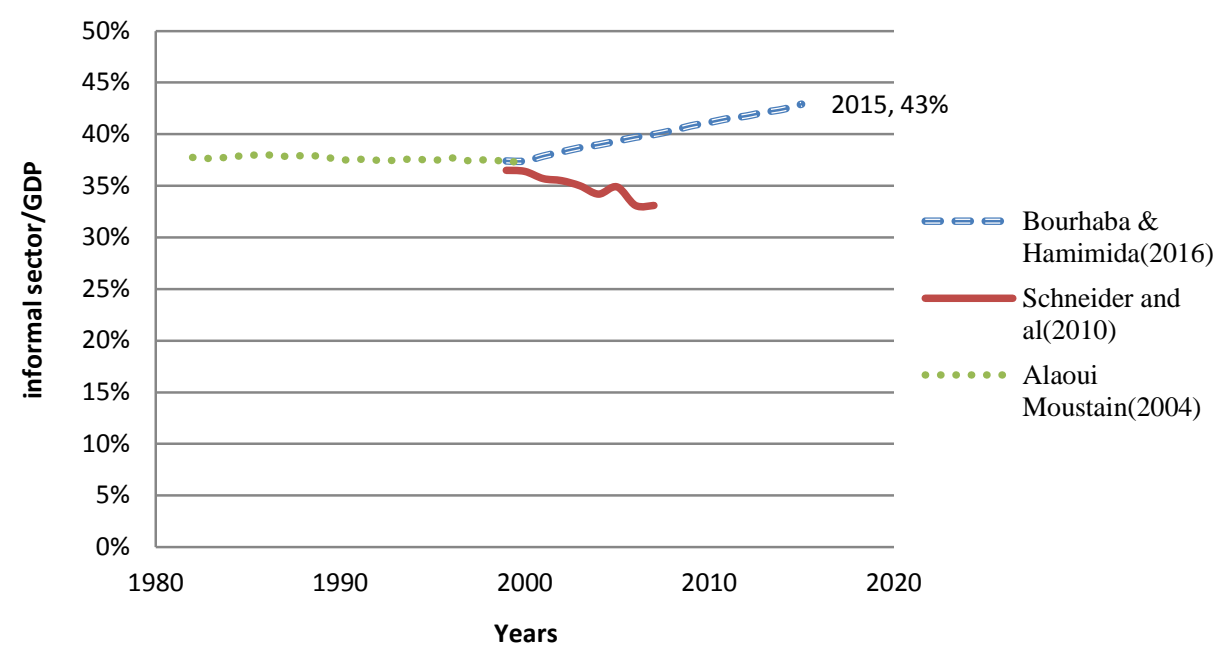

Figure 2. Size of informal sector in Morocco as percentage of official GDP

Source: the authors' calculation.

The estimate size of the informal economy shows that there are differences in results due to differences in methods. Although, all the estimations turn around 35\% - 40\% as a percentage of GDP.

When we think about the absolute size of the informal economy, we should realize that all the estimates are approximate because of the complex nature of the informal sector and the difficulties one meets at its extent.

\section{Conclusion}

In order to estimate the size of the informal economy in Morocco, we have used the MIMIC approach. We find that the size of the informal economy in Morocco is equal to 43\% of GDP in 2015. The main cause of the informal economy in Morocco is urbanization. In addition, the tax burden also played a critical role in increasing the size of the informal economy. An increase of the tax burden by $1 \%$ leads to an increase in the informal economy size by $0.11 \%$. Another important reason that has an impact on the size of the informal economy in Morocco is corruption.

To provide a brief economic explanation of our results, we can say, first, that urbanization is a consequence of economic development, when a country starts to develop its economy, by industrialization and services, cities become more attractive for rural population. An increase of the rural flight leads to the overpopulation of the cities. The formal sector has not got the capacity to absorb all the labor force in the labor market. Hence, a part of this labor force goes to the informal sector.

Second, we assume that corruption plays a determinate role in the magnification of the informal economy. Although the theoretical link is not clear in the literature, empirical studies show that there is a positive relationship between the informal economy and corruption. The assumption is that when economic agents found a corrupt administration they prefer to choose the informal sector to avoid regulation and maximize their profits because this corrupt administration will have an attitude of letting things happen and will not impose regulation on individuals who plays in the dark economy. Hence, an improvement of the quality of institutions will lead to reducing the size of the informal economy.

Finally, the tax burden is one of the most popular determinant causes of the magnification of the informal economy. Simply, because individuals try to hide their output to avoid taxation. High taxation contributes to the amplification of the informal economy and then the reduction of government revenue. In accordance with the Laffer curve, high taxation leads to less revenue for the state because individuals will lie about their real revenue and production.

Although the critics, the MIMIC approach still the best method to estimate the size of informal sector, but this method requires extensive data in order to give reliable results. One of the limitations of our study is that we don't have a large amount of data. The problem of availability of data is a common problem for developing countries. Future works with extensive data or a new approach of measure are welcomed in this area of research.

These results are important to have a real view of the size of the economy, because traditional indicators, such as 
GDP do not always give the true picture of the economy. In order to establish a good economic policy, government must first know the real size of the economy. Now, with an informal sector that constitutes $43 \%$ of GDP in 2015, we believe that it is important to take this sector into account in policy making.

\section{References}

Alaoui, M. F. Z. (2004). Market distortions and the informal economy: The case of Morocco. Economics Working Paper Series. The Department of Economics, Lancaster University.

Breusch, T. (2005). Estimating the underground economy using MIMIC models. Working paper, Canberra, Australia.

Del'Anno, R., \& Schneider, F. G. (2006). Estimating the Underground Economy by Using MIMIC Models: A Response to T. Breusch's Critique. Economics working papers. Department of Economics, Johannes Kepler University Linz, Austria.

Del'Anno, R. (2003). Estimating the shadow economy in Italy: A structural equation approach. Discussion Paper, Department of Economics and Statistics, University of Salerno.

Dell'Anno, R. (2007). The Shadow Economy in Portugal: An Analysis with the MIMIC Approach. Journal of Applied Economics, 10(2), 253-277.

Dell'Anno, R., Gómez, A. M., \& Alañon, P. A. (2007). The shadow economy in three Mediterranean countries: France, Spain and Greece. A MIMIC approach. Empirical Economics, 33(1), 197-197. http://dx.doi.org/10.1007/s00181-007-0138-1

Elgin, C., \& Oyvat, C. (2013). Lurking in the cities: Urbanization and the informal economy. Structural Change and Economic Dynamics, Elsevier, 27(C), 36-47. http://dx.doi.org/10.1016/j.strueco.2013.06.003

Elgin, C., \& Oztunali, O. (2012). Shadow Economies around the World: Model Based Estimates. Working Papers 2012/05, Bogazici University.

Frey, B. S., \& Weck, H. (1983). Bureaucracy and the Shadow Economy: A Macro-Approach. In Anatomy of Government Deficiencies. Horst Hanusch, Springer, pp. 89-109. http://dx.doi.org/10.1007/978-3-66221610-1_6

Giles, D. E. A. (1999). Measuring the hidden economy: Implications for econometric modeling. The Economic Journal, 109(456), 370-380. http://dx.doi.org/10.1111/1468-0297.00440

Giles, D. E. A., \& Tedds, L. M. (2002). Taxes and the Canadian Underground Economy. Canadian Tax Foundation, Toronto.

Hart, K. (1973). Informal Income Opportunities and Urban Employment in Ghana. The Journal of Modern African Studies, 11(1), 61-89. http://dx.doi.org/10.1017/S0022278X00008089

Hoyle, R. H. (1995). The structural equation modeling approach: Basic concepts and fundamental issues. In Structural equation modeling: Concepts, issues, and applications. In R. H. Hoyle (Ed.), Thousand Oaks (pp. 1-15). CA: Sage Publications, Inc.

Klarić, V. (2011). Estimating the size of non-observed economy in Croatia using the MIMIC approach. Financial Theory \& Practice, 35(1), 59-90.

Lewis, W. A. (1954). Economic Development with Unlimited Supplies of Labour. The Manchester School, 22(2), 139-191. http://dx.doi.org/10.1111/j.1467-9957.1954.tb00021.x

Loayza, N. A. (1997). The economics of the informal sector: A simple model and some empirical evidence from Latin America. Policy Research Working Paper Series 1727, The World.Bank.

Loayza, N., \& Rigolini, J. (2006). Informality Trends and Cycles. Research Working Paper No. 4078. World Bank Policy. http://dx.doi.org/10.1596/1813-9450-4078

Schneider, F. (2002). The Size and Development of the Shadow Economies of 22 Transition and 21 OECD Countries. IZA Discussion Paper No. 514, University of Linz and IZA Bonn.

Schneider, F., \& Enste, D. (2002). The Shadow Economy: Theoretical Approaches, Empirical Studies, and Political Implications. Cambridge (UK): Cambridge University Press.

Schneider, F., Buehn, A., \& Montenegro, C. E. (2010). Shadow economies all over the world: New estimates for 162 countries from 1999 to 2007. Policy Research Working Paper Series 5356, the World Bank. 


\section{Notes}

Note 1. Dell'Anno (2007) is the author who influenced the most the construction of our model.

Note 2. NGO founded in 1993 is today present in more than 100 countries, it is primarily intended to fight corruption.

Note 3. See Loayza (1997), Loayza and Rigolini (2006).

Note 4. For more details, see Dell'anno, Gomez and Alanon (2007).

Note 5. Dell'anno and Schneider (2006) present a state of art on benchmarking procedures.

\section{Appendix}

Appendix 1. Annual estimates of the informal economy in Morocco

\begin{tabular}{llc}
\hline Years & Informal economy \\
\hline 1999 & $37,41 \%$ \\
2000 & $37,40 \%$ \\
2001 & $37,88 \%$ \\
2002 & $38,29 \%$ \\
2003 & $38,69 \%$ \\
2004 & $38,97 \%$ \\
2005 & $39,34 \%$ \\
2006 & $39,71 \%$ \\
2007 & $39,97 \%$ \\
2008 & $40,35 \%$ \\
2009 & $40,81 \%$ \\
2010 & $41,14 \%$ \\
2011 & $41,51 \%$ \\
2012 & $41,76 \%$ \\
2013 & $42,13 \%$ \\
2014 & $42,42 \%$ \\
2015 & $42,91 \%$ \\
\hline
\end{tabular}

Source: the authors' calculations.

\section{Copyrights}

Copyright for this article is retained by the author(s), with first publication rights granted to the journal.

This is an open-access article distributed under the terms and conditions of the Creative Commons Attribution license (http://creativecommons.org/licenses/by/4.0/). 